\title{
Histomorphological Spectrum of Nephrectomy Specimens- A Tertairy Care Centre Experience
}

\author{
VIKRAM NARANG, BHAVNA GARG, ASHNEET WALIA, NEENA SOOD, VINEETA MALHOTRA
}

\section{ABSTRACT}

Introduction: Nephrectomy is a common surgical procedure done for a variety of neoplastic and nonneoplastic diseases. This study has been taken up to analyze kidney diseases histopathologically and various lesions of the kidney and their subtypes and record the various lesions which have lead to partial nephrectomy, total nephrectomy, unilateral and bilateral nephrectomies.

Aim: To study spectrum of diseases in nephrectomy specimens, histological sub typing of neoplastic conditions and evaluation of histopathological prognostic features like capsular invasion, vascular invasion and nuclear grade.

Materials and Methods: This was an retrospective and prospective analysis done over the period of 4 years (2006-2009). A nephrectomy specimens received in the Department of Pathology Dayanand Medical College and Hospital, Ludhiana were analyzed with respect to gross and microscopic features.

Results: Out of a total number of 155 cases, 82 were neoplastic, 73 were non-neoplastic males were 98 and females 57 with a M:F ratio 1.7:1. Out of the 82 neoplastic cases, Renal cell carcinoma (Clear cell type) was commonest (57 cases) followed by Transitional cell carcinoma (07 cases), Papillary RCC (03 cases), Oncocytoma (03 cases), Wilm's tumour (02 cases), RCC with sarcomatoid change (02 cases), RCC unclassifiable (03 cases) and 01 case each of Chromophobe RCC, Multicystic RCC, Collecting duct carcinoma and small round cell tumour respectively. Of the 73 non-neoplastic cases, chronic pyelonephritis with hydronephrosis constituted 42 cases, emphysematous pyelonephritis (16 cases), xanthogranulomatous pyelonephritis (02 cases), acute or chronic pyelonephritis (09 cases), polycystic kidney (02 cases), cystic renal dysplasia and tuberculosis (01 case each).

Conclusion: Radical nephrectomy is the common surgical procedure done for both neoplastic disorders as well as non neoplastic lesions. Detailed histopathological examination is necessary for diagnosis and the prognostication of the lesions.

Keywords: Chronic pyelonephritis, Clear cell renal cell carcinoma, Histopathology, Renal cell carcinoma

\section{INTRODUCTION}

Nephrectomy is a common surgical procedure which is done in a variety of neoplastic and non neoplastic conditions. It can either be simple in which only kidney is removed and is mainly done for non neoplastic conditions or radical nephrectomy which is usually performed for renal neoplasms and it involves removal of gerotas fascia and its entire contents including kidney, perinephric fat and ipsilateral adrenal gland [1]. Partial nephrectomy is indicated in bilateral renal cell carcinoma or renal cell carcinoma involving a solitary functioning kidney. The common non-neoplastic diseases, for which nephrectomy is usually performed are non- functioning kidney due to severe hydronephrosis, pyonephrosis, polycystic kidneys etc. Nephrectomy remains the standard of care for patients with a suspected renal mass. Accurate pathological evaluation of renal neoplasms is essential for subtyping (clear cell carcinoma, papillary renal cell carcinoma, chromophobe carcinoma, transitional cell carcinoma etc.,) proper staging i.e nuclear grading, capsular and vascular invasion and thus, assisting in establishing further treatment protocols [2].

In this study analysis of various neoplastic and non neoplastic conditions in nephrectomy specimens was done. Histopathological sub typing of all neoplasms was done and various histopathological prognostic factors like capsular/ vascular invasion and nuclear grade were studied.

\section{MATERIALS AND METHODS}

This was a retrospective and prospective analysis done over the period of 4 years (2006-2009). A nephrectomy specimens received in the Department of Pathology Dayanand Medical College and Hospital, Ludhiana were analyzed with respect to 
gross and microscopic features. The patients who underwent core needle biopsies from their renal masses were excluded. In each patient the clinical findings such as age, sex and relevant investigations and pathological findings i.e gross and microscopic features were recorded as per predesigned proforma. For neoplastic lesions, the tumour was identified and gross features i.e. size, colour location, capsular involvement, haemorrhagic areas etc., were recorded. The hematoxylin and eosin stained slides were critically analysed and special stain like PAS, Masson trichrome, Zeihl Nelson etc., were done wherever required.

Grossing of the formalin fixed nephrectomy specimens was done according to the standard procedure. After routine paraffin processing, sections of $3 \mu \mathrm{m}$ thickness were cut and routinely stained with haematoxylin and eosin stain. Detailed light microscopic features were studied and recorded. The final diagnosis was arrived at after correlating the clinical features, gross and microscopic findings. Special stains and immunohistochemistry were used as and when required. All the diseases were classified as neoplastic or non-neoplastic and a specific diagnosis was given wherever possible. The non-neoplastic diseases were further classified as congenital malformations including cystic diseases of kidney, obstructive uropathy and tubulointerstitial diseases. Histological typing of all neoplasms was done according to WHO classification and their histological prognostic factors i.e. nuclear grade, capsular invasion, infiltration into the peri-renal fat and vascular invasion were evaluated.

\section{STATISTICAL ANALYSIS}

Ethical approval from the ethical committee of the institute was taken and a descriptive analysis of the data was done and no statistical analysis was required.

\section{RESULTS}

A total of 155 total nephrectomy specimens were received out of which 82 cases were neoplastic and 73 were non neoplastic lesions with a male to female ratio of $1.7: 1$. The age ranged varied widely according to the type of the disease. The youngest patient in the series being a 2 year male while oldest being an 80 years old male. Patients operated for non-neoplastic disorders were younger (mean age 45.1 years) than those operated for neoplastic disorders (mean age 51.4 years).

\section{Non Neoplastic Lesions}

The non-neoplastic lesions constituted 73 cases with chronic pyelonephritis being the commonest cause (44 cases) leading to nephrectomy. Chronic pyelonephritis with hydronephrosis was the commonest indication for nephrectomy accounting for $60.3 \%$ cases of non-neoplastic category. All these kidneys were enlarged with majority had coarse depressed scars. The pelvicalyceal system was dilated and distorted. The microscopy showed varying degrees of glomerular atrophy and hyalinization, periglomerular fibroses, tubular atrophy and hyalinization along with interstitial inflammation, fibrosis and thickened blood vessels. Xanthogranlomatous pyelonephritis (2 cases) was diagnosed as there were yellowish nodular foci grossly and microscopic examination revealed sheets of foamy microphages along with acute and chronic inflammatory cells were also included. Second most common benign entity was emphysematous pyelonephritis (16 cases). There was an associated history of diabetes in all of them. Females were more commonly affected and all the cases had a history of long standing diabetes mellitus. Grossly there were small cystic spaces. Microscopic examination revealed a dense acute and chronic inflammatory infiltrate along with presence of small cystic spaces.

The other lesions included acute or chronic pyelonephritis, polycystic diseases, cystic renal dysplasia and tuberculosis.

\section{Neoplastic Lesions}

Renal neoplasms constituted 82 cases. Clear cell RCC was the commonest (57 cases) followed by transitional cell carcinoma of renal pelvis (7 cases). Others included Papillary RCC, RCC unclassifiable and oncocytoma (3 cases each.) There were 2 cases each of Wilms tumour and RCC with sarcomatoid change. There was one case each of chromophobic RCC, Multicystic RCC, collecting duct carcinoma, small round cell tumour and an interesting case of synchronous Transitional Cell Carcinoma with clear cell Renal cell carcinomas were distributed from 21-80 years with a definite peak in $4^{\text {th }}$ and $5^{\text {th }}$ decade. Nephroblastoma were diagnosed in first decade of life. Overall M:F ratio was 1.9:1. The neoplasms were common on the right side (53.6\%) as compared to left side (46.4\%). The tumour size ranged from $2 \mathrm{~cm}$ to $20 \mathrm{~cm}$ [Table/Fig-1].

The clear cell renal cell carcinomas were graded from 1 to 4 according to Fuhrman's nuclear grade. Nuclear grade 2 were most common (54.4\%) followed by Nuclear Grade 3 (31.6\%) [Table/Fig-2]. Capsular invasion was seen in 05, vascular invasion in 03, adrenal invasion in 01 and renal sinus invasion in 08 cases. No case of ureteral or lymphatic invasion was encountered.

Transitional cell carcinomas were noticed in 7 cases accounting for $8.5 \%$ of total renal neoplasms. These tumours were located in renal pelvis and more so in right kidney (5 cases). Majority of them (6 cases) were high grade while only one was a low grade neoplasm.

An interesting case observed was of synchronous transitional cell carcinoma high grade, and clear cell renal cell carcinoma 


\begin{tabular}{|c|c|c|}
\hline Diagnosis & $\begin{array}{c}\text { Number of } \\
\text { cases }(\mathrm{N}=155)\end{array}$ & $\begin{array}{c}\text { Percentage } \\
(\%)\end{array}$ \\
\hline NON-NEOPLASTIC & 73 & 47.1 \\
\hline Chronic Pyelonephritis & 44 & 28.4 \\
\hline Emphysematous Pyelonephritis & 16 & 10.3 \\
\hline Acute or Chronic Pyelonephritis & 09 & 5.8 \\
\hline Polycystic Kidney & 02 & 1.3 \\
\hline Cystic Renal Dysplasia & 01 & 0.6 \\
\hline Tuberculosis & 01 & 0.6 \\
\hline NEOPLASTIC & 82 & 52.9 \\
\hline Clear Cell RCC & 57 & 36.8 \\
\hline Transitional Cell Carcinoma & 07 & 4.5 \\
\hline Papillary RCC & 03 & 1.9 \\
\hline Oncocytoma & 03 & 1.9 \\
\hline RCC unclassifiable & 03 & 1.9 \\
\hline Wilm's Tumour & 02 & 1.3 \\
\hline RCC with Sarcomatoid Change & 02 & 1.3 \\
\hline Chromophobe RCC & 01 & 0.6 \\
\hline Multicystic RCC & 01 & 0.6 \\
\hline Collecting Duct Carcinoma & 01 & 0.6 \\
\hline Small Round Cell Tumour & 01 & 0.6 \\
\hline $\begin{array}{l}\text { Synchronous TCC } \\
\text { and Clear Cell RCC }\end{array}$ & 01 & 0.6 \\
\hline
\end{tabular}

[Table/Fig-1]: Relative frequency of various disorders affecting the kidney.

\begin{tabular}{|c|c|}
\hline Nuclear Grade & Number of cases \\
\hline 1 & 05 \\
\hline 2 & 31 \\
\hline 3 & 18 \\
\hline 4 & 03 \\
\hline
\end{tabular}

[Table/Fig-2]: Fuhrman's nuclear grading for clear cell rcc.

observed in the same kidney in a 38 years old male. Capsular invasion was seen in 05, vascular invasion in 03, adrenal invasion in 01 and renal sinus invasion in 08 cases. No case of ureteral or lymphatic invasion was encountered.

\section{DISCUSSION}

Nephrectomy is a standard treatment offered to patients who present with benign as well as malignant mass lesions in the kidney. Most common malignant tumour in adults is renal cell carcinoma (RCC) and Wilms tumour in childhood. Rare are urothelial tumours of calyces and pelvis. Renal cell carcinoma (RCC) accounts for 1 to $3 \%$ of all visceral cancers and $85 \%$ of renal cancers. Affect older individuals usually in the $6^{\text {th }}$ and $7^{\text {th }}$ decades and show male preponderance (2 to $3: 1$ ). Risk factors include tobacco intake, obesity, hypertension, unopposed estrogen therapy, exposure to asbestos, chronic renal failure, acquired cystic disease and tuberous sclerosis complex patients $[1,2]$. Most renal carcinomas are sporadic. Familial variants (4\%) consisting of Von Hippel-Lindau (VHL) Syndrome, Hereditary (familial) clear cell carcinoma and Hereditary papillary carcinoma.

$\mathrm{RCC}$ is a great mimicker and has features of Paraneoplastic syndrome [3].

In the present study for neoplastic disorders (82 cases $-52.9 \%)$ were slightly more than those done for non neoplastic conditions (73 cases $-47.1 \%$ ) in the ratio of 1.1:1. This is in accordance with studies conducted by Bersland et al., (30.8\% non-neoplastic) and Danenport et al., (48.6\% non-neoplastic) [4,5]. Number of nephrectomies done for non-neoplastic conditions has declined because of better antibiotic availability and minimally invasive techniques used these days for treatment of kidney stones. Also patients are being treated at an earlier stage.

We encountered male preponderance with a M:F ratio of 1.7:1 which was also noted by Neggada et al., (1.6:1) and Eke $\mathrm{N}$ et al., (1.6:1) [6-8]. The predominant population in which nephrectomies was done was $3^{\text {rd }}$ to $5^{\text {th }}$ decade. Mean age for non-neoplastic disorders was 45 years while neoplastic diseases were 52 years. Out of 73 cases of non-neoplastic disorders, infective pathology formed a predominant subgroup of 70 cases. Hence, there is a need to emphasize the importance of early diagnosis and proper treatment of urinary tract infections and nephrolithiasis. Other conditions encountered were cystic renal dysplasia and polycystic kidney disease

Emphysematous pyelonephritis accounted for 22\% (16 cases) of all the non-neoplastic lesions. Females were more commonly affected and all the cases had a history of long standing diabetes mellitus. This high number of cases can be attributed to marked increases in the incidence of diabetes in India. Also since ours is a reference center these cases get clustered in our institute.

In our study there was only one case of tuberculosis. The probable reason for this low incidence is better antitubercular treatment and also since our hospital caters to a better socioeconomic population so tuberculosis is treated at a much earlier stage.

There were 82 cases renal tumours; out of which 70 (85.3\%) cases were of renal cell carcinoma followed by transitional cell carcinoma 7 cases (8.5\%). Similar results were also shown by Beisland et al., who had $72.7 \%$ cases of RCC and $21.9 \%$ cases of TCC Jha et al., had $87.3 \%$ cases of RCC and $12.6 \%$ cases of T.C.C. while Ali Tebibi et al., encountered $84.6 \%$ cases of RCC and $4.7 \%$ cases of TCC $[5,9,10]$.

Among 70 cases of renal cell carcinoma clear cell RCC was most common accounting for 57 cases while there were 3 
cases each of papillary RCC \& RCC unclassifiable 2 cases of sarcomatoid RCC and 1 case each of chromophobe RCC, collecting duct CA and multicystic RCC were noted. This is in accordance with many other studies like Zou et al., (67.5\%) cases Cheville et al., (83.2\% cases) [11,12]. Low grade RCC (nuclear grade 1 and 2) comprised of $63.1 \%$ case while high grade RCC (nuclear grade 3 and 4) comprised of $36.9 \%$ cases. Sriwastrva et al., also had $52.8 \%$ low grade tumours $[13,14]$.

One interesting case of multilocular cystic RCC was also observed which was characterized by multiple cysts of varying size with presence fibrous septae separating the cysts. These septae contained round to polygonal tumour cells with clear cytoplasm. There were 3 cases (4.2\%) which could not be ascertained to a definite histologic subtype.

In our study we had three cases of Wilms tumour $(2.4 \%$ cases). Ali Tabibi et al., also had only $1.4 \%$ cases of Wilms tumour in their study [9].

\section{CONCLUSION}

Open nepherectomy still remains treatment of choice for the both benign and malignant renal masses. The detailed histopatholoical examination is essential to classify the lesions and grade the neoplastic ones as these help in deciding the treatment protocols.

\section{REFERENCES}

[1] WHO classification of Tumours: Pathology and genetics of tumours of urinary system and male genital organ. 2004; 9-87.

[2] Amin MB, Corless CL, REnshaw AA, Tickoo SK, Rubus J, Schultz DS. Papillary (chromophil) renal cell carcinoma, histomorphological characteristics and evaluation of conventional pathological prognostic parameter in 62 cases. Am J Surg Pathol. 1997;21(6):621-35.

[3] Kim K, CHO C. Analysis of the causes of nephrectomy in 19802005. Korean Journ of Urol. 2007;48:775-81.

[4] Davenport K, Temoney AG, Reeley FX: A 3 year review of British association of urological surgeons sections of endourology laproscopic nephrectomy audit. BJ U Int. 2005; 97: 333-37.

[5] Beisland C, Medley PC, Sander S. Nephrectomy indications complications and postoperative mortality in 646 consecutive patients. Eur Urol. 2000; 37: 58-64.

[6] Ghalyini IF. Pathological spectrum of nephrectomies in a general hospital. Asian J Surg. 2002;25 (2):163-69.

[7] Nggada HA, Eni UE, Nwankuro EA. Histopathological finding in nephrectomy specimens. A review of 42 cases. Niger Postgrad Med. J. 2006; 13(3):244-46.

[8] Eke N, Echen RC, Nephrectomy at the university of part Harconsist Teaching Hospital; a ten year experience. Afer J Med Sci. 2003; 32(2):173-77.

[9] Tabibi A, Parvin M, Abdi H, Bashtar R, Zamani N. Correlation between size of renal cell carcinoma and its grade, stage and histological subtype. Urol J. 2008; 4: 10-13.

[10] Jha MS, Gupta N, Agrawal S, Ansari MS, Dubey D Mandhani A et al. Single centre experience of laproscopic nephrectomy: impact of learning curve on outcome. Indian J Urol. 2007;23 (3):253-56.

[11] Zou H,Pang LJ, HuWH, Li F, Li HA, Jiang JF etal. Study on clinicopathologic features of 114 cases of renal cell carcinoma. Zhonghua Bing Li Xue Za Zhi. 2008;37:726-31

[12] Cheville JC, Lohse CM, Zincke $H$, Weaver AL, Blute ML. Comparison of outcome and prognostic features among histologic subtypes of renal cell carcinoma. Am J Surg Pathol. 2003; 27:612-24.

[13] Fuhrman SA, Lasky LC, Limas C. Prognostic Significance of Morphological parameters in renal cell carcinoma. Am J Surg Path. 1982; 6: 655-63.

[14] Srivastava A, Mandhani A, Kapoor R, Jain M, Dubey D, Raghavendra MA et al. Prognostic factors in patients with renal cell carcinoma: Is TNM (1997) staging relevant in Indian subpopulation. Indian J Cancer. 2004; 41:99-103.

\section{AUTHOR(S): \\ 1. Dr Vikram Narang \\ 2. Dr Bhavna Garg \\ 3. Dr Ashneet Walia \\ 4. Dr Neena Sood \\ 5. Dr Vineeta Malhotra}

\section{PARTICULARS OF CONTRIBUTORS:}

1. Assistant Professor, Department of Pathology, Dayanad Medical College and Hospital, Ludhiyana, Punjab, India.

2. Professor, Department of Pathology, Dayanad Medical College and Hospital, Ludhiyana, Punjab, India.

3. Ex Resident, Department of Pathology, Dayanad Medical College and Hospital, Ludhiyana, Punjab, India.

4. Professor and Head, Department of Pathology,
Dayanad Medical College and Hospital, Ludhiyana, Punjab, India.

5. Former Professor and Head, Department of Pathology, Dayanad Medical College and Hospital, Ludhiyana, Punjab, India.

\section{NAME, ADDRESS, E-MAIL ID OF THE CORRESPONDING AUTHOR:}

Dr Vikram Narang,

Assitant Profeesor, Department of Pathology, Dayanand Medical College And Hospital, Ludhiana, Punjab-141001, India.

Email: drvikramnarang@yahoo.com

FINANCIAL OR OTHER COMPETING INTERESTS: None. 